\title{
A rostral neurovascular system in the mosasaur Taniwhasaurus antarcticus
}

\author{
Gerardo Álvarez-Herrera ${ }^{1}$ • Federico Agnolin ${ }^{1,2,3} \cdot$ Fernando Novas $^{1,3}$
}

Received: 15 November 2019 / Revised: 3 April 2020 / Accepted: 10 April 2020

(C) Springer-Verlag GmbH Germany, part of Springer Nature 2020

\begin{abstract}
Mosasaurs were a cosmopolitan group of marine squamate reptiles that lived during the Late Cretaceous period. Tylosaurinae mosasaurs were characterized for having an edentulous rostrum anterior to the premaxillary teeth. External morphology of the snout of the tylosaurine Taniwhasaurus antarcticus from the Upper Cretaceous beds at James Ross Island (Antarctic Peninsula) shows a complex anatomy with diverse large foramina and bone sculpture. A computed tomography scan of the Taniwhasaurus rostrum revealed a complex internal neurovascular system of branched channels in the anteriormost part of the snout. Systems like this are present in extant aquatic vertebrates such as cetaceans and crocodiles to aid them with prey detection, and are inferred to have functioned in a similar manner for several extinct reptile clades such as plesiosaurs and ichthyosaurs. Thus, it is probable that Taniwhasaurus also was able to detect prey with an enhanced neural system located in its rostrum. This condition may be more widespread than previously thought among mosasaurs and other marine reptiles.
\end{abstract}

Keywords Mosasaur $\cdot$ Tylosaurinae $\cdot$ Neurovascular system $\cdot$ Trigeminus nerve

\section{Introduction}

In many extant amniote groups, there are mechanosensory or electrosensory organs associated within the rostrum and the mandible that are innervated by the ophthalmic and the maxillary rami of the trigeminal nerve, especially in those secondarily aquatic. These specialized sensory organs include infrared receptors in ophidians (Loop and Schroeder 1975), DPRs in crocodilians (dome pressure receptors; Soares 2002),

Communicated by: Aurora Grandal-d'Anglade

Electronic supplementary material The online version of this article (https://doi.org/10.1007/s00114-020-01677-y) contains supplementary material, which is available to authorized users.

Gerardo Álvarez-Herrera

geralvarezherrera@gmail.com

1 Laboratorio de Anatomía Comparada y Evolución de los Vertebrados, Museo Argentino de Ciencias Naturales "Bernardino Rivadavia", Av. Ángel Gallardo 470, C1405DJR Buenos Aires, Argentina

2 Fundación de Historia Natural "Félix de Azara", Universidad Maimónides, Hidalgo 775, C1405BDB Buenos Aires, Argentina

3 CONICET, Buenos Aires, Argentina vibrissae in mammals (Ahl 1986; Mauck et al. 2000), and the electrosensory and mechanosensory organs in Ornithorhynchus (Pettigrew 1999). For these animals, having extra sensory organs is a useful and necessary trait in habitats with weak light conditions.

Recently, using computed tomography, related internal structures were proposed for different marine reptiles, such as plesiosaurs (Foffa et al. 2014; O'Gorman and Gasparini 2013), ichthyosaurs (Kear 2005; Lomax et al. 2019, and references therein), and crocodylomorphs (George and Holliday 2013; Leicht and Catania 2012; Soares 2002), and were thought to belong to branches of the trigeminal nerve as well, serving to enhance skin sensitiveness. Furthermore, even some terrestrial dinosaurs exhibited similar structures (Barker et al. 2017; Cau et al. 2017; Ibrahim et al. 2014), suggesting that specialized sensory organs were convergently acquired, and were more widely distributed than previously thought.

The presence of a high number of large foramina in the tip of the snout of an exceptionally preserved skull of the mosasaur Taniwhasaurus antarcticus (Novas et al. 2002) leads us to hypothesize the presence of an internal neurovascular system. This is the first time that such structures are described for a mosasaur. 


\section{Materials and methods}

The studied specimen IAA 2000-JR-FSM-1 is the holotype of Taniwhasaurus antarcticus, a tylosaurine mosasaur from the Snow Hill Formation (Campanian-Maastrichtian, Olivero 2012), at James Ross Island (Antarctica). The muzzle of the specimen was CT scanned at the TCba Salguero Diagnostic Center (Buenos Aires City, Argentina), using a GE Brightspeed Elite 16 slice CT scanner medical tomographer. The slice thickness was $1.25 \mathrm{~mm}$, and the scan energy parameters were $140 \mathrm{mAs}$ and $120 \mathrm{kV}$. The resolution of the

a

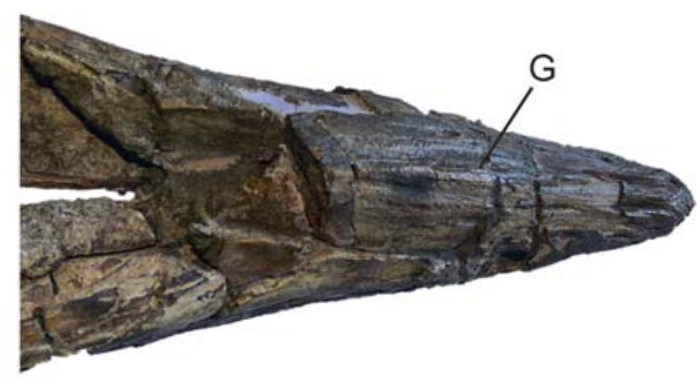

C

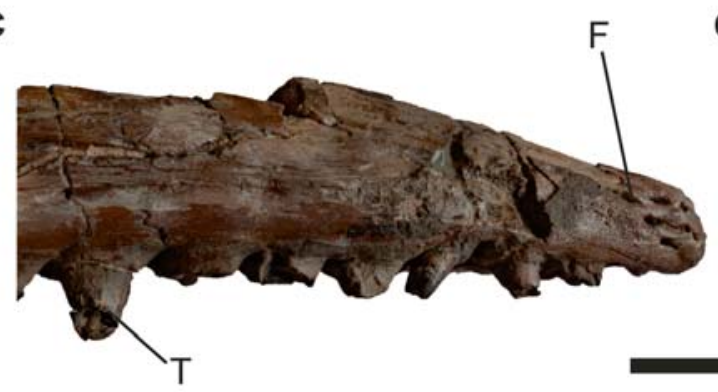

e

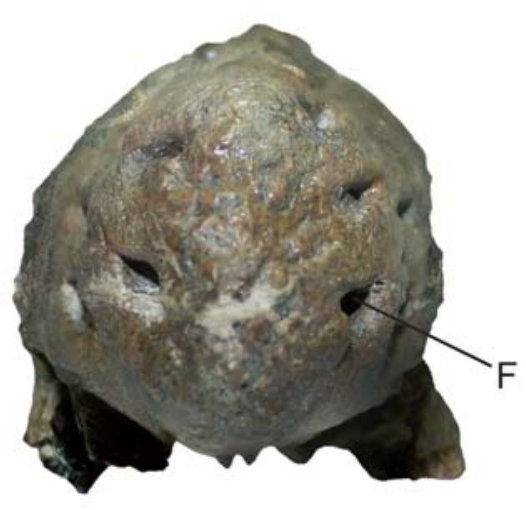

resulting data was $0.586 \times 0.586 \times 1.25 \mathrm{~mm} / \mathrm{voxel}$, and produce 332 slices. The DICOM data were analyzed with the $3 \mathrm{D}$ Slicer 4.10.0. The model is shown as a supplementary 3D PDF, which was made with the DesignSpark Mechanical 4.0.

\section{Results}

The scanned material revealed an internal complex internal network of branched canals (Fig. 1, red) that we interpret as part of the neurovascular system. These canals are located

b

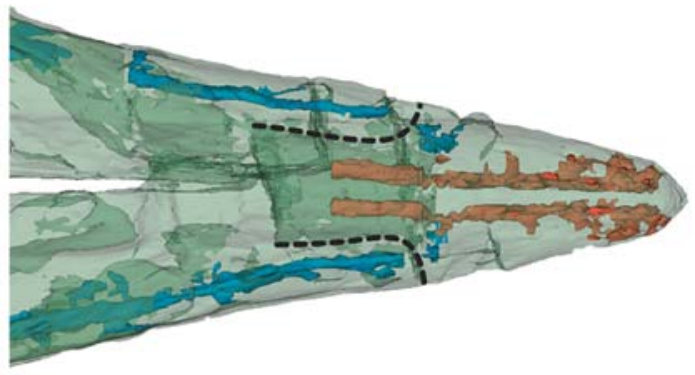

d

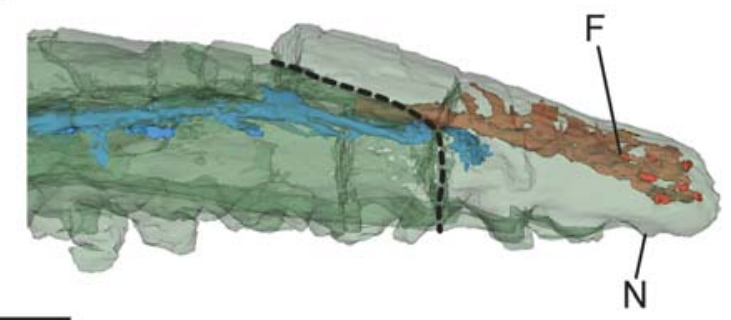

f

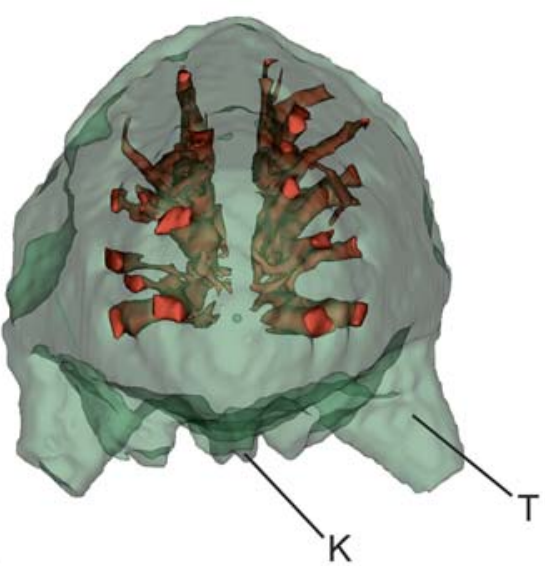

Fig. 1 Taniwhasaurus antarcticus, IAA 2000-JR-FSM-1, fragmentary maxillae and premaxilla, fossil $(\mathbf{a}, \mathbf{c}, \mathbf{e})$ and $3 \mathrm{D}$ model $(\mathbf{b}, \mathbf{d}, \mathbf{f})$, in dorsal (a, b), right lateral (c, d), and frontal (e, f) views. Model images show the ramus maxillaris (blue) and the ramus ophthalmicus (red) of trigeminal nerve. $\mathbf{e}$ and $\mathbf{f}$ are detailed frontal view of premaxilla, where the yellow lines represent the three main planes of distribution of terminal nerves. Dotted lines represent the maxillae-premaxilla limit. Scale bar equals $5 \mathrm{~cm}$ for $\mathbf{a}-\mathbf{d}$ and $2 \mathrm{~cm}$ for e, f. F, foramina; G, grooves; N, nubbin; $\mathrm{T}$, teeth; $\mathrm{K}$, medial ventral keel 
Fig. 2 Comparison between snouts of crocodiles $(\mathbf{a}, \mathbf{d})$, Taniwhasaurus antarcticus (b, e), and Pliosaurus kevani (c). The terminals of the ramus maxillaris and the ramus ophthalmicus are painted in blue and red, respectively. In c, purple represents a structure conformed by both rami. In e, dotted lines represent the putative limits of cranium; all the gray areas represent the actual preserved material and the light gray the scanned portion. TG, trigeminal ganglion; N, narial apertures. Modified from Cau et al. 2017 (a); Foffa et al. 2014 (c); and Leitch and Catania 2012 (d)
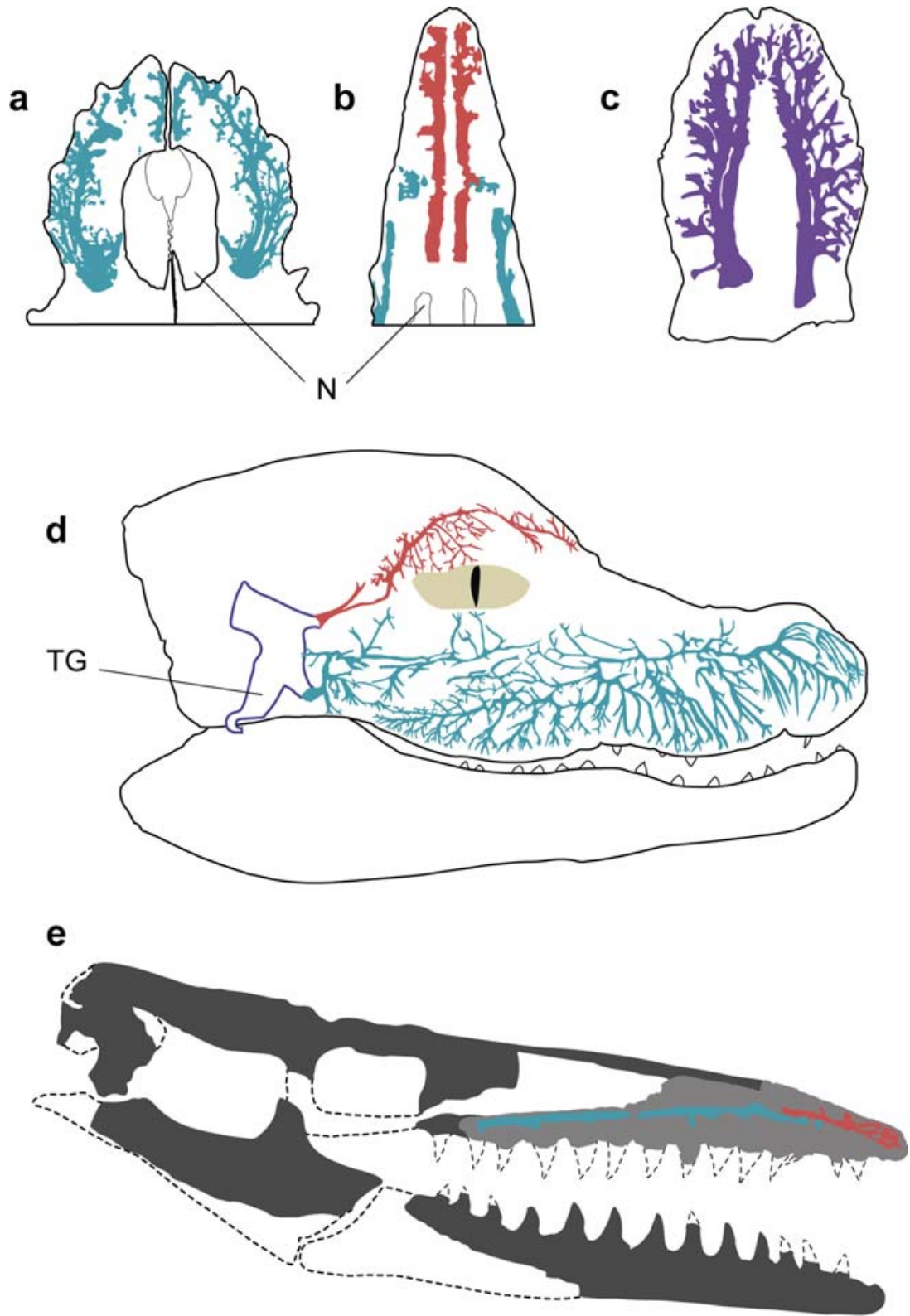

mostly in the tip of the premaxilla. The canals run paired through maxillae-premaxilla contact, enter the latter, and then branch off profusely at the tip of the premaxilla. Many of these terminal branches exit the bone by foramina located in the dorsolateral surface of the snout (Fig. 1, right, red). The canals are five millimeters in width at their bases, while the distal terminals are $1.5-2 \mathrm{~mm}$ in diameter. The analysis also reveals an outer canal in a ventrodorsal position in both maxillae (Fig. 1 , blue), which runs longitudinally and reaches only the posterior portion of premaxilla. These canals have branches in the maxilla and exit the bone through a row of foramina parallel to the teeth row. The two sets of canals do not contact each other at any point (see also supplementary information).

The most anterior canals (i.e., red canals, Fig. 1) enter the premaxilla subhorizontally at the level of the second maxillary tooth, and immediately, the first branches orient towards a dorsal position but do not reach the bone surface. At the level of the first premaxillary teeth, there occurs a major branching, with each canal bifurcating up to three times. The resulting canals are almost straight, with few branches.

The main canals are symmetrical in the transverse section (Fig. 1f) and generate up to 16 terminals on each side, of which nine to eleven leave superficial foramina. Eight foramina are located anterior to the first premaxillary tooth in the edentulous rostrum typical for tylosaurines. Furthermore, six of these foramina are at the level of the "nubbin," which in tylosaurines is also present on the ventral surface of the rostrum. This "nubbin" may represent the anterior limit of the gum line (Russell 1967, p. 16). The foramina are associated with shallow anteroposteriorly oriented grooves (Fig. 1a) that 
become smaller towards the anterior end of the rostrum until they disappear at the level of the nubbin. The branches of these canals reach only the dorsolateral surface of the premaxilla, and they do not reach any premaxillary alveoli.

\section{Discussion}

Comparisons with extant varanoids (Bellairs 1949) and other squamates (Abdel-Kader et al. 2011; Dakory and Shamakh 2008) indicate that the main canals here described are terminals of the ramus nasalis medialis (medial ethmoidal nerve, sensu Bellairs 1949), and a branch of the ramus nasalis (one of the two main branches of the ramus ophthalmicus of trigeminus nerve). The ramus nasalis medialis enters the premaxilla and gives off the rami premaxillaris superior and premaxillaris inferior, the former exiting dorsally in the premaxilla. Due to the branching pattern and the position of the exit foramina, we agree with Russell (1967) that the foramina represent the exit of the ramus ophthalmicus of trigeminus nerve and, more precisely, the ramus premaxillaris superior. These nerves send sensitive information from the skin of the snout to the brain and have only two exit foramina at the tip of the premaxilla in extant Varanus (see Bellairs 1949). On the other hand, the canals in the maxillae (Fig. 1, blue) are interpreted as the ramus maxillaris of the trigeminal nerve (Romer 1956), and they have a similar branching pattern to most squamates, parallel to the teeth row to innervate the gum (Soares 2002).

Here, we interpret the profusely branched nerves in the premaxilla as a highly sensitive neurovascular system, innervated by the trigeminal nerve. Therefore, a mechanosensory or electrosensory rostral organ is hypothesized in a mosasaur for the first time. This assumption is based on similarities with other extinct clades in which this kind of structure would have developed, such as plesiosaurs or ichthyosaurs. Among these similarities are the holes present in the maxilla and/or premaxilla, and a neural network innervated by one or more branches of the trigeminal nerve.

Although the DPR described for crocodiles (Soares 2002, Fig. 2a, d) has a similar internal morphology to the canals of Taniwhasaurus, the foramina of Taniwhasaurus are bigger, fewer in number, and do not have the hexagonal pattern described for crocodiles (Fig. 2b). Besides, the Taniwhasaurus snout is innervated by the ramus ophthalmicus of the trigeminal nerve, while in crocodiles, this branch does not reach the snout, and the ramus maxillaris is the one that branches profusely and innervates the skin of the snout (Fig. 2d, e).

The internal neurovascular structure of Taniwhasaurus differs from that found in some pliosaurs (Foffa et al. 2014, Fig. 2c) in that the former has no terminals that reach any alveoli and the branching is not related to alveoli, and the main canals run closer to each other in Taniwhasaurus. Also, the grooves are shallower, and the foramina are fewer in Taniwhasaurus. Besides, the main canals are innervated by both rami maxillaris and ophthalmicus in pliosaurs. In some polycotylids (O'Gorman and Gasparini 2013) and ichthyosaurs (Lomax et al. 2019), the foramina are disposed in a main groove, whereas in extant squamates, a row of foramina is present and related to the gum tissue (Soares 2002). In this aspect, Taniwhasaurus differs from these taxa in that it is innervated by the ramus ophthalmicus, which is confined to the premaxilla and is not arranged in rows. Thus, structures like the aforementioned seem to appear in marine reptiles convergently many times under the same selective pressures. Despite morphological differences, the gross morphology of the neurovascular system of Taniwhasaurus is similar to the condition of pliosaurs, and thus, a similar function is considered likely, that is, detect movement of potential preys in low light conditions.

Even though Taniwhasaurus seems to have particularly large foramina on its snout, the presence of large pits on the snout was also observed in other mosasaurs (Lingham-Soliar 1995; Konishi et al. 2012; Russell 1967). Those pits may indicate the presence of a complex neurovascular system in other mosasaurs, being probably a widespread condition among the clade. Furthermore, tylosaurines seem to display the largest snout foramina among mosasaurs. This condition may correlate with the modified edentulous rostrum that characterizes this family (Russell 1967), but further studies are necessary to test these two hypotheses.

Acknowledgments Special thanks to Ignacio Poyo, to the TCba Salguero Diagnostic Center (Buenos Aires, Argentina), and to the Jaime Roca Foundation in lending us the necessary equipment and providing us with scanned images that were crucial for the present contribution. We also thank Julia D'Angelo, Sebastián Rozadilla, Adriel Gentil, and Mauricio Cerroni for their help during the development of present the work.

\section{References}

Abdel-Kader TG, Ali RS, Ibrahim NM (2011) The cranial nerves of Mabuya quinquetaeniata III: Nervus Trigeminus. Life Sci J 8(4): 650-669

Ahl AS (1986) The role of vibrissae in behavior: a status review. Vet Res Commun 10(1):245-268. https://doi.org/10.1007/BF02213989

Barker CT, Naish D, Newham E, Katsamenis OL, Dyke G (2017) Complex neuroanatomy in the rostrum of the Isle of Wight theropod Neovenator salerii. Sci Rep 7(1):3749. https://doi.org/10.1038/ s41598-017-03671-3

Bellairs AA (1949) Observations on the snout of Varanus, and a comparison with that of other lizards and snakes. J Anat 83(2):116-146

Cau A, Beyrand V, Voeten DF, Fernandez V, Tafforeau P, Stein K, Godefroit P (2017) Synchrotron scanning reveals amphibious ecomorphology in a new clade of bird-like dinosaurs. Nature 552(7685):395-399. https://doi.org/10.1038/nature24679

Dakory AI, Shamakh AED (2008) The ethmoidal ganglion and its anatomical relations in Lacertilia (Squamata: Reptilia). J Am Sci 7(8): 526-532. https://doi.org/10.7537/marsjas070811.59 
Foffa D, Sassoon J, Cuff AR, Mavrogordato MN, Benton MJ (2014) Complex rostral neurovascular system in a giant pliosaur. Naturwissenschaften 101(5):453-456. https://doi.org/10.1007/ s00114-014-1173-3

George ID, Holliday CM (2013) Trigeminal nerve morphology in Alligator mississippiensis and its significance for crocodyliform facial sensation and evolution. Anat Rec 296(4):670-680. https://doi. org/10.1002/ar.22666

Ibrahim N, Sereno PC, Dal Sasso C, Maganuco S, Fabbri M, Martill DM, Iurino DA (2014) Semiaquatic adaptations in a giant predatory dinosaur. Science 345(6204):1613-1616. https://doi.org/10.1126/ science. 1258750

Kear BP (2005) Cranial morphology of Platypterygius longmani Wade, 1990 (Reptilia: Ichthyosauria) from the lower cretaceous of Australia. Zool J Linnean Soc 145(4):583-622. https://doi.org/10. 1111/j.1096-3642.2005.00199.x

Konishi T, Lindgren J, Caldwell MW, Chiappe L (2012) Platecarpus tympaniticus (Squamata, Mosasauridae): osteology of an exceptionally preserved specimen and its insights into the acquisition of a streamlined body shape in mosasaurs. J Vertebr Paleontol 32(6): 1313-1327. https://doi.org/10.1080/02724634.2012.699811

Leitch DB, Catania KC (2012) Structure, innervation and response properties of integumentary sensory organs in crocodilians. J Exp Biol 215(23):4217-4230. https://doi.org/10.1242/jeb.076836

Lingham-Soliar T (1995) Anatomy and functional morphology of the largest marine reptile known, Mosasaurus hoffmanni (Mosasauridae, Reptilia) from the Upper Cretaceous, Upper Maastrichtian of the Netherlands. Philos Trans R Soc Lond Ser B Biol Sci 347(1320):155-180. https://doi.org/10.1098/rstb.1995. 0019

Lomax DR, Porro LB, Larkin NR (2019) Descriptive anatomy of the largest known specimen of Protoichthyosaurus prostaxalis (Reptilia: Ichthyosauria) including computed tomography and digital reconstruction of a three-dimensional skull. PeerJ 7:e6112. https://doi.org/10.7717/peerj.6112

Loop MS, Schroeder DM (1975) Some afferent connections of trigeminal system in snakes possessing facial infrared receptors. Anat Rec 181(2):413-413

Mauck B, Eysel U, Dehnhardt G (2000) Selective heating of vibrissal follicles in seals (Phoca vitulina) and dolphins (Sotalia fluviatilis guianensis). J Exp Biol 203(14):2125-2131

Novas FE, Fernández M, de Gasparini ZB, Lirio JM, Nuñez HJ, Puerta P (2002) Lakumasaurus antarcticus, n. gen. et sp., a new mosasaur (Reptilia, Squamata) from the Upper Cretaceous of Antarctica. Ameghiniana 39(2):245-249

O'Gorman JP, Gasparini Z (2013) Revision of Sulcusuchus erraini (Sauropterygia, Polycotylidae) from the Upper Cretaceous of Patagonia, Argentina. Alcheringa 37(2):163-176

Olivero EB (2012) Sedimentary cycles, ammonite diversity and palaeoenvironmental changes in the Upper Cretaceous Marambio Group, Antarctica. Cretac Res 34:348-366. https://doi.org/10. 1016/j.cretres.2011.11.015

Pettigrew JD (1999) Electroreception in monotremes. J Exp Biol 202(10): $1447-1454$

Romer AS (1956) Osteology of the reptiles. University of Chicago Press, Chicago

Russell D (1967) Systematics and morphology of American mosasaurs. Peabody Museum Natural History, Yale University Bulletin 23:1241

Soares D (2002) An ancient sensory organ in crocodilians. Nature 417(6886):241-242. https://doi.org/10.1038/417241a

Publisher's note Springer Nature remains neutral with regard to jurisdictional claims in published maps and institutional affiliations. 